Tohoku J. Exp. Med., 2017, 243, 49-56

Review

\title{
Musical Instrument-Associated Health Issues and Their Management
}

\author{
Kae Okoshi, ${ }^{1}$ Taro Minami, ${ }^{2}$ Masahiro Kikuchi ${ }^{3}$ and Yasuko Tomizawa ${ }^{4}$ \\ ${ }^{1}$ Department of Surgery, The Japan Baptist Hospital, Kyoto, Kyoto, Japan \\ ${ }^{2}$ Division of Pulmonary, Critical Care, and Sleep Medicine, Memorial Hospital of Rhode Island, The Warren \\ Alpert Medical School of Brown University, Pawtucket, RI, USA \\ ${ }^{3}$ Department of Otolaryngology-Head and Neck Surgery, Kobe City Medical Center General Hospital, Kobe, \\ Hyogo, Japan \\ ${ }^{4}$ Department of Cardiovascular Surgery, Tokyo Women's Medical University, Tokyo, Japan
}

\begin{abstract}
Playing musical instruments can bring joy to people, but can also cause a wide variety of health issues that range from mild disorders to potentially fatal conditions. Although sports medicine is an established medical subspecialty, relatively few studies have investigated the health issues associated with musical instruments. Here we present an overview of these health issues. These include infections due to microorganisms, allergic reactions, as well as mechanical injuries from sustained high pressures within the oral, mediastinal, thoracic, and abdominal cavities. For example, wind instruments can potentially harbor thousands of pathogenic organisms. If several players share the same instrument, these instruments present potential hazards in the spread of infections. A fatal case of hypersensitivity pneumonitis in a bagpiper is particularly noteworthy. Similarly, a case of gastrointestinal anthrax in an animal-hide drummer is a reminder of this rare but highly fatal disease. Although not fatal, hearing-related disorders, neuromuscular issues, musculoskeletal problems, and contact dermatitis are also very common among instrumentalists. This review aims to illuminate these under-recognized health issues by highlighting both the common conditions and the rare but fatal cases.
\end{abstract}

Keywords: gastrointestinal anthrax; hypersensitivity pneumonitis; inguinal hernia; musical instruments; spontaneous pneumomediastinum

Tohoku J. Exp. Med., 2017 September, 243 (1), 49-56. C 2017 Tohoku University Medical Press

\section{Introduction}

Playing musical instruments can bring joy to musicians and the people around them. However, this activity is also responsible for numerous health issues that range from mild disorders to potentially fatal conditions. A recent report by King and coworkers described a fatal case of hypersensitivity pneumonitis (HP) in a bagpiper, which provides a stark reminder of the risk of health issues associated with musical instruments (King et al. 2017).

All instrumental musicians, including professional performers, teachers, students, and amateurs, face the risk of developing a wide range of health issues. Although sports medicine has become an established medical subspecialty, less attention has been paid to the health issues of instrumentalists (Lederman 2003).

Here, we review and discuss the various health issues associated with musical instruments and their management.

\section{Hypersensitivity Pneumonitis}

The first few cases of HP were originally described in farmers exposed to moldy hay or straw (Campbell 1932). Since then, HP has also been found to be associated with multiple inhaled antigens in numerous environmental settings. This condition is triggered by an excessive immune response that induces acute infection-like symptoms and increasingly severe lung damage (Girard et al. 2009). While fatalities due to HP are rare, the continuous and intense exposure to HP antigens may lead to death in some cases (Dickson and Tankersley 2015). In Japan, there have been several reports of HP associated with home ultrasonic humidifiers (Nakagawa et al. 1995; Higuchi et al. 2011; Takagi et al. 2012).

In addition, there have been case reports of HP occurring in saxophonists (Lodha et al. 1988; Metzger et al. 2010; Rackley and Meltzer 2011), a trombonist (Metersky et al. 2010), and a bagpiper (King et al. 2017). In the latter-

Received June 20, 2017; revised and accepted August 23, 2017. Published online September 21, 2017; doi: 10.1620/tjem.243.49.

Correspondence: Kae Okoshi, M.D., Ph.D., Department of Surgery, The Japan Baptist Hospital, 47 Yamonomoto-cho, Kitashirakawa,

Sakyo-ku, Kyoto, Kyoto 606-8273, Japan.

e-mail: kae_md@kuhp.kyoto-u.ac.jp 
most case, a 61-year-old man who played the bagpipes daily was referred to an interstitial lung disease clinic with a 7-year history of dry cough and progressive dyspnea on exertion with poor exercise tolerance. He was prescribed 2 $\mathrm{mg} / \mathrm{kg}$ azathioprine with prednisolone, but continued to play the bagpipes daily. Five months after the initial visit to the interstitial lung disease clinic, he was hospitalized due to deterioration of symptoms and died one month later (King et al. 2017).

HP in instrumental musicians is likely caused by the inhalation of one or more types of microorganisms such as Candida albicans (Lodha et al. 1988), Ulocladium botrytis, and Phoma sp. (Metzger et al. 2010). Mycological samples from a patient's saxophone revealed fungal contamination by U. botrytis and Phoma sp. (Metzger et al. 2010). In another case study, cultures of the biofilm found inside the patient's trombone revealed large numbers of Mycobacterium chelonae-abscessus group and Fusarium sp., as well as minute quantities of Stenotrophomonas maltophilia and Escherichia coli (Metersky et al. 2010). The study by King et al. (2017) detected a wide range of fungi in the patient's bagpipes that included Paecilomyces variotii, Fusarium oxysporum, Penicillium sp., Rhodotorula mucilaginosa, Trichosporon mucoides, pink yeast, and Exophiala dermatitidis. The various types of potentially pathogenic fungi sampled from various wind instruments are summarized in Table 1.

Patients with instrument-derived HP may reduce the severity of their symptoms by ceasing to play contaminated instruments. However, this can be problematic in professional musicians who rely on these instruments to make a living. In particular, there may be an overall lack of education provided to students on the correct methods to clean wind instruments (King et al. 2017). The mouthpieces of instruments can harbor thousands of microorganisms that survive for several days. Walter and Chaffey (1959) reported that large numbers of bacteria are deposited in the mouthpiece when a wind instrument is played. These instruments can act as fomites for pathogenic microorganisms if the same instrument is used by several players, which is common in schools. Cleaning mouthpieces by brushing it 15 times with a commercial detergent-sanitizer solution within a 30 -second period has been shown to greatly reduce bacterial counts (Walter and Chaffey 1959). This cleaning procedure not only sanitizes the mouthpiece, but also helps to prevent accumulation of organic material in the shank. Cleaning instruments immediately after use and allowing them to drip-dry would theoretically reduce the overall risk of microorganism growth, although the impact of this cleaning method on the growth of fungi has yet to be assessed (King et al. 2017).

\section{Tuberculosis and Other Lung Infections}

Tuberculosis (TB) was rampant throughout Japan prior to World War II. Despite a subsequent decline in the number of infected cases, the incidence of TB still remains relatively high among Japanese people older than 60 years of age. On the other hand, it was reported that $1 \%$ of those aged below 20 years and $2 \%$ of those aged below 30 years were infected with TB in 1995 (Mori 2000). A study in Japan reported the possibility of TB transmission from one university student (with a Gaffky count of 2) to other students who had played the same trumpet in the same room of a wind ensemble club (Nohga et al. 1989). While none of the other students developed TB, 38.7\% of the club members demonstrated a positive reaction $(>30 \mathrm{~mm}$ in diameter) to the tuberculin skin test (Nohga et al. 1989).

Marshall and Levy (2011) assessed the survivability of potential pathogens (e.g., Staphylococcus sp., Streptococcus sp., Moraxella sp., E. coli, and attenuated Mycobacterium tuberculosis) when inoculated onto clarinet reeds or following simulated playing. All species survived for a maximum of 24 to 48 hours on the reeds, except M. tuberculosis, which persisted for as long as 13 days (Marshall and Levy 2011). These bacteria can survive and proliferate on the mouthpieces of wind instruments, and subsequently colonize the instrument bodies. In this way, the sharing of instruments by several players may present a potential route for TB transmission.

\section{Asthma and Pulmonary Function Deterioration}

Deniz et al. (2006) reported that pulmonary function in wind instrumentalists can be diminished due to the development of asthma or the sustained barotrauma experienced

Table 1. Mycological samples from wind instruments.

\begin{tabular}{|c|l|l|l|}
\cline { 2 - 4 } \multicolumn{1}{c|}{} & Bagpipes & Trombone & Saxophone \\
\hline \multirow{5}{*}{ Mycological } & Paecilomyces variotii & Paecilomyces variotii & Ulocladium botrytis \\
& Fusarium oxysporum & Fusarium oxysporum & Phoma sp. \\
& Penicillium sp. & Penicillium sp. & \\
& Rhodotorula mucilaginosa & Candida albicans & \\
& Trichosporon mucoides & & \\
& Exophiala dermatitidis & & \\
& Phoma sp. & & \\
\hline
\end{tabular}

Adapted from Metersky et al. (2010), Metzger et al. (2010), and King et al. (2017). 
during playing. In a comparison of wind instrumentalists and healthy individuals, that study found statistically significant differences in the following pulmonary function parameters: forced vital capacity, forced expiratory volume in 1 second (FEV1), peak expiratory flow rate, forced expiratory flow (FEF) 25-75, FEF25, FEF50, and FEF75. The differences between the groups were more evident in small airway parameters such as FEF25, FEF50, FEF75, and FEF25-75.

In contrast, Fuhrmann et al. (2011) reported that wind or brass instrumentalists did not have poorer respiratory function when compared to a control group. However, the instrumentalists in their study demonstrated increased respiratory resistance, which may indicate inflammation, remodeling, or other pathophysiological processes associated with playing these instruments. Another previous study had also found no significant differences in asthma prevalence between wind/brass musicians and other musicians in Australia (Fuhrmann et al. 2009). Respiratory diseases can severely affect wind instrumentalists, and bronchial asthma is the most common chronic pulmonary disorder among these musicians. However, therapeutic programs that include breath training and physical exercise have been shown to improve symptoms, endurance, and general wellbeing (Gilbert 1998). The playing of wind instruments requires musicians to have considerable lung volume and mechanical force of respiratory muscles, skilled breath control, sufficient lung patency, air passage humidity, and coordination of the oropharyngeal cavity (Deniz et al. 2006).

Although a previous study proposed that the playing of wind instruments may be associated with lung cancer, that study had used a relatively small sample size of 132 lung cancer patients and 182 controls (Ruano-Ravina et al. 2003). Further research using larger samples should be conducted to verify the influence of wind instruments on the respiratory system.

\section{Spontaneous Pneumomediastinum}

Spontaneous pneumomediastinum refers to the unexplained presence of free air in the mediastinum. This condition excludes cases with clear etiology, including those caused by infections, trauma, and iatrogenic injuries. Spontaneous pneumomediastinum is uncommon and relatively benign, and occurs most frequently in young adults. Common clinical manifestations include chest pain, dyspnea, and subcutaneous emphysema. Due to this low incidence, previous studies have mainly focused on case series and case reports (Macia et al. 2007). One study reported that young trumpet players had higher maximum respiratory pressures than young people who did not play wind instruments, and that these musicians are at greater risk of mechanical injury to oral and cervical tissues due to the generation of high peak expiratory pressures (Fiz et al. 1993). Another study reported the maximum average expiratory pressure values to be 150,50 , and $25 \mathrm{~cm} \mathrm{H}_{2} \mathrm{O}$ in people who play the trumpet, flute, and oboe, respectively
(Bouhuys 1969).

A case report described a 16-year-old boy who played the trumpet at school and developed who had two different disorders (pneumomediastinum and pharyngeal protrusion) due to increased airway pressure (Flores-Franco and LimasFrescas 2010). In Japan, studies have reported cases of spontaneous pneumomediastinum associated with playing the trumpet (Hayashi et al. 2003) and trombone (Ito et al. 1989).

\section{Anthrax}

Anthrax is an often-fatal infection caused by Bacillus anthracis, a sporulating Gram-positive bacterium (Owen et al. 2015). This zoonotic disease is mainly associated with herbivores and domesticated animals, and occurs more frequently in countries where animal vaccination is uncommon. Anthrax is rare in humans, and usually occurs due to close contact with infected domesticated animals (including cattle and goats) or their products such as skin, meat, hides, and bones (Goel 2015). The bacteria can infect humans through the cutaneous, gastrointestinal (GI), or respiratory routes (Dixon et al. 1999). Based on a case series study, the mortality rates associated with cutaneous, GI, and inhalation anthrax have been estimated to be $1 \%, 25-60 \%$, and $46 \%$, respectively (Sweeney et al. 2011).

The US Centers for Disease Control and Prevention (CDC) reported the case of a man who developed inhalation anthrax after exposure to animal-hide drums in 2006 (CDC 2006). The patient was a New York City resident who travelled to northern Pennsylvania, where he collapsed with rigors and was hospitalized. A chest $\mathrm{x}$-ray revealed bilateral opacities and pleural effusions. The patient reported suffering from shortness of breath, dry cough, and malaise for 3 days. As a result of this case, the CDC released recommendations for drum makers, drum owners, and drummers to report new skin lesions or severe respiratory conditions, and to disclose any contact with animal hide-related products (CDC 2006). Similarly, a fatal case of inhalation anthrax due to contact with animal-hide drums was reported in the UK in 2008 (Anaraki et al. 2008).

In 2007, a physician in the US reported two suspected cases of cutaneous anthrax to the Connecticut Department of Public Health; one was a male drum maker who worked with untreated goat hides from Guinea, West Africa and the other was his 8-year-old child (CDC 2008). The drum maker reported feeling a sting on his right forearm while sanding a newly assembled goat-hide drum. Two days later, he developed a painless 2-cm papular lesion with surrounding edema, and the lesion subsequently progressed to an eschar with lymphangitic spread. His child had most likely also been exposed to the contaminated drum (CDC 2008).

In 2010, the CDC (2010) reported a case of GI anthrax in a 24-year-old woman after an animal-hide drumming event. Computed tomography (CT) scanning of her abdomen and pelvis revealed numerous ascites, no bowel dilata- 
tion, and concentric wall thickening in the distal small bowel. There were multiple enlarged lymph nodes at the root of the small-bowel mesentery and in the retroperitoneum. The patient underwent exploratory laparotomy, which found large quantities of ascites; nodular, hemorrhagic lesions in the mesentery; and two regions of necrotic small bowel. Biopsy samples from the mesenteric lesions, necrotic bowel, and appendix indicated transmural hemorrhage, edema, and acute inflammation with necrosis in the small intestine. The patient also had diffuse hemorrhage with acute inflammation and necrosis in the lymph nodes, and the diagnosis of anthrax was confirmed by a positive blood culture of B. anthracis (Klempner et al. 2010). Qualitative environmental sampling at the drumming event site also detected $B$. anthracis from two drums and three electrical outlets (CDC 2010; Klempner et al. 2010).

GI anthrax usually results from the consumption of contaminated meat (Fasanella et al. 2010, Goel 2015). In the GI anthrax case described above, the patient had eaten dinner in the main drumming room, but had only consumed vegetarian food (CDC 2010). It is possible that drumming on an anthrax-contaminated animal-hide drum may have caused a brief aerosolization of anthrax spores, which were then inhaled and ingested by the patient (Klempner et al. 2010).

In abdominal GI anthrax, lesions are formed mainly in the ileum and cecum. The incubation period is 3 to 7 days, and the symptoms include headache, nausea, diarrhea, bloody vomiting, abdominal pain, and ascites (Goel 2015). The risk of infection from handling animal-hide drums or attending events where such drums are played is very low. However, the CDC (2010) cautions that physicians treating patients with symptoms compatible with anthrax (such as unexplained fever, skin lesions, a serious respiratory or gastrointestinal illness) should be aware of the possible connection between anthrax and animal-hide drums.

\section{Inguinal Hernia}

Playing wind instruments is accompanied by increased intra-abdominal and intrathoracic pressure. Wind instrumentalists are therefore likely to be at higher risk for inguinal hernia despite a current lack of definitive evidence (Vosk 2009). A study that measured bladder pressure (which is indicative of intra-abdominal pressure) in trumpet players showed that rising tones and higher playing volume increased the pressures in the oral cavity and urinary bladder equally, with a maximum pressure of $140 \mathrm{mmHg}$. The study also measured bladder pressure during other activities, such as lifting $20 \mathrm{~kg}$, yelling, laughing and coughing, and doing nothing (Table 2) (Rietveld 2007). Vosk (2009) also reported a case of a bagpiper who developed inguinal hernia.

Furthermore, physicians and surgeons should carefully monitor high intra-abdominal pressure in wind instrumentalists with previous history of inguinal hernia in order to prevent recurrence. Because these musicians are consistently exposed to high intra-abdominal pressure, the laparoscopic transabdominal preperitoneal technique has been recommended for treating trumpet players with inguinal hernia (Rietveld 2007).

\section{Spermatic Cord Hematoma}

Lindhorst and Paolucci (2000) described a patient who experienced a spermatic cord hematoma shortly after playing the saxophone. The patient had undergone left inguinal hernia repair 35 years prior, and stopped playing the saxophone after the surgery. However, he played the saxophone for the first time in 35 years and experienced sudden pain with increasing swelling of his left groin. The pathophysiology of delayed bleeding in the inguinal region after inguinal hernia repair is unclear. However, Lindhorst and Paolucci (2000) speculated that postoperative changes due to scar formation and changes in blood flow may have contributed to the development of hematoma in their patient.

\section{Spontaneous Spinal Epidural Hematoma}

Spinal epidural hematoma is a rare clinical entity that presents with severe acute pain followed by progressive motor and sensory impairment (Guzel et al. 2007). A case study described a 23-year-old male professional trumpet player who presented with spontaneous spinal epidural hematoma after a performance (David et al. 1997). While the exact cause of spontaneous bleeding remains unclear, spontaneous spinal epidural hematoma is generally considered to be the result of bleeding from the epidural venous plexus in the spinal epidural space due to the lack of venous valves, and undulating pressure from the thoracic and abdominal cavities can directly impact this condition (Riaz

Table 2. Measurements of bladder pressure, an indicator of intra-abdominal pressure, when playing trumpet and performing other activities.

\begin{tabular}{|c|c|c|c|c|c|c|}
\hline & \multirow{2}{*}{$\begin{array}{c}\text { Base } \\
\text { level }\end{array}$} & $\begin{array}{c}\text { Low tones } \\
\text { and low } \\
\text { volume }\end{array}$ & $\begin{array}{c}\text { High tones and } \\
\text { high volume }\end{array}$ & $\begin{array}{c}\text { Lifting 20 } \\
\mathrm{kg}\end{array}$ & Yelling & $\begin{array}{c}\text { Laughing } \\
\text { and } \\
\text { coughing }\end{array}$ \\
\hline $\begin{array}{c}\text { Pressure } \\
\text { (mmHg) }\end{array}$ & $0-10$ & 45 to 60 & $\leq 140$ & 20 & 85 & 120 \\
\hline
\end{tabular}

Adapted from Rietveld (2007). 
et al. 2007). Increased blood pressure in vulnerable vessels has also been identified as a possible mechanism of spontaneous spinal epidural hematoma (Guzel et al. 2007).

\section{Laryngocele}

Laryngocele refers to the dilatation of a laryngeal saccule. This condition may result from a congenitally large saccule, mechanical obstruction by tumors including malignancies, or prolonged periods of increased laryngeal pressure. The incidence of this condition is extremely rare, with an estimated one case per 2.5 million population per year in the UK (Stell and Maran 1975). However, the playing of wind instruments has been identified as a risk factor of laryngocele development (Stell and Maran 1975, Prasad et al. 2008). Most laryngoceles occur unilaterally (87.3\%) (Zelenik et al. 2014). Laryngoceles are categorized as either an internal type (accounting for 59\% of all cases) if they are confined within the larynx or a combined type (accounting for $41 \%$ of all cases) if they extend externally through the thyrohyoid membrane (Zelenik et al. 2014). Common symptoms include hoarseness (internal type) or a soft, reducible upper neck mass that increases in size with the Valsalva maneuver (combined type). However, laryngoceles can also be incidentally detected in asymptomatic patients who undergo neck CT scanning or nasopharyngeal fiberscopic examination. Physicians should note that approximately $10 \%$ of laryngoceles present as airway emergencies (Zelenik et al. 2014), and emergent extirpation of a laryngocele with or without tracheostomy may be necessary, especially in case of patients with large internal laryngoceles.

\section{Pneumoparotid (Pneumoparotitis)}

Pneumoparotid is a rare clinical entity that manifests as the presence of air within one or both parotid glands. When accompanied by inflammation, this condition is known as pneumoparotitis. This is usually caused by increased oral pressure and the retrograde flow of air and saliva through Stensen's duct (McGreevy et al. 2013). Wind instrumentalists have an elevated risk for the development of pneumoparotitis (Saunders 1973; Kyung et al. 2010). Other risk factors include diving (Watt 1977), dental treatment (Piette and Walker 1991), general anesthesia (known as anesthesia mumps) (Reilly 1970; Kimura et al. 1993), nose blowing during allergic rhinitis (Garber 1987), and an unconscious or deliberate habit of self-insufflation (Goguen et al. 1995; Gudlaugsson et al. 1998). Swelling and pain of the parotid glands are common and often recurrent (Han and Isaacson 2004). Treatment includes the use of antibiotics for cases with bacterial infection and surgical interventions (including salivary duct ligation or parotidectomy) for recurrent cases with severe symptoms. For wind instrumentalists, however, teaching techniques to reduce air insufflation may be a better management approach (Luaces et al. 2008). Surgeons must keep in mind that severe pneumoparotitis may exacerbate to subcutaneous emphysema of the face or neck, and even to pneumomediastinum through the parapharyngeal and retropharyngeal spaces (Gudlaugsson et al. 1998).

\section{Hearing Loss and Hearing-Related Disorders}

Hearing loss and hearing-related disorders (such as tinnitus, hyperacusis, and feelings of pain or pressure in the ears) in musicians can be caused by sustained exposure to loud music (Stormer et al. 2015). Schink et al. (2014) reported that professional musicians had a four-fold higher adjusted hazard ratio for noise-induced hearing loss and a $57 \%$ higher adjusted hazard ratio for tinnitus when compared with the general population. A pathological characteristic of noise-induced hearing loss is the loss of auditory sensory cells in the cochlea (Basner et al. 2014).

Only a small percentage of musicians use hearing protection devices to prevent damage to their auditory system (Santucci 2009; Pouryaghoub et al. 2017). This may indicate a need for educational programs for musicians to become more aware of the risks of noise exposure. The further development of specialized devices for hearing loss protection may also help to reduce hearing-related issues in musicians.

Due to the widespread use of personal music players, the general population is also at increased risk for noiseinduced hearing loss or hearing-related disorders. Jiang et al. (2016) found that a large proportion of adolescents and young adults that use personal music players are at risk of noise-induced hearing loss, especially when they listen to music at volumes exceeding $65 \mathrm{~dB}$ for extended periods of time. In a recently published systematic review, hearing thresholds at higher frequencies $(4-16 \mathrm{kHz})$ were significantly poorer in personal music player users when compared with control subjects (le Clercq et al. 2016). In this way, noise-induced hearing loss is no longer limited to occupational exposure to sustained noise, but is becoming increasingly common in recreational settings.

\section{Stomatognathic Problems}

Long-term and repetitive playing of musical instruments, particularly stringed instruments (such as violins and violas) and wind instruments, can result in dysfunction of the stomatognathic system (Glowacka et al. 2014). The intense playing of a musical instrument may predispose players to the development of dysfunction in the temporomandibular joint. Kovero et al. (1997) compared the bony facial dimensions between adolescent violin students and non-violinist controls, and found that the former tended to have higher faces, especially on the right lower face and mandibular ramus. In addition, the violinists had more proclined upper and lower incisors than the controls. The authors concluded that the greater facial height in the violinists was indicative of increased facial muscle activity, and that the higher bony dimensions of the right side of the face were a result of increased muscular activity to compensate for the load generated by the violin on the left side. 
The greater proclination of the incisors was postulated to be the result of unequal muscular activity between the tongue and lip, as well as the pressure of the violin onto the chin (Kovero et al. 1997).

Gunst et al. (2011) reported two cases of external cervical resorption on maxillary incisors. The authors suggested that the primary etiologic factor was pressure trauma due to the frequent playing of wind instruments. This activity generates repetitive forces comparable to excessive and long-term orthodontic forces, which can in turn trigger and stimulate external cervical resorption.

\section{Elevation of Intraocular Pressure}

Studies have suggested that the elevation of intraocular pressure (IOP) when playing a wind instrument with high resistance can result in increased uveal volume due to repetitive Valsalva maneuvers (Schuman et al. 2000; Mete et al. 2016). This action generates an elevated IOP by increasing intrathoracic pressure and compression of the intrathoracic venous system (Sihota et al. 2008). Schmidtmann et al. (2011) noted that fluctuations in IOP with transient large elevations due to playing increases the risk of glaucoma in professional wind instrumentalists. Accordingly, these musicians should be monitored for signs and symptoms of glaucoma, especially in those with coexisting risk factors.

\section{Neuromuscular and Musculoskeletal Problems}

Playing a musical instrument involves a series of actions performed over long periods of time. These actions include rapid, repetitive, and complicated movements of the hands and fingers. A systematic review of musculoskeletal disorders in professional violinists and violists found that these musicians most commonly suffered from problems in the neck, shoulder, and temporomandibular joints due to prolonged flexion of the head and shoulder when holding the instrument; the elbow and fingers were also found to be common sites of disorders (Moraes and Antunes 2012). Nyman et al. (2007) reported that many violinists and violists $(35.3 \%$ of the study sample) suffered from neck and shoulder pain. In addition, the reported prevalence rates for musculoskeletal disorders in pianists have varied widely (26-93\%) (Bragge et al. 2006). When compared with musicians who play the piano as their main instrument, those who mainly play the violin or viola have a four-fold higher incidence of right elbow/forearm disorders and a two-fold higher incidence of neck pain, right shoulder pain, and left elbow/forearm pain (Hagberg et al. 2005). In addition, flautists may be at an elevated risk of musculoskeletal symptoms due to their asymmetrical playing posture and the constant supporting of their instrument against gravity (Lonsdale et al. 2014).

\section{Contact Dermatitis}

Skin conditions affect not only professional instrumentalists, but are also a problem in amateur musicians regard- less of age or ability. Contact dermatitis is the most prevalent skin disorder experienced by instrumentalists. This is particularly the case among string musicians (e.g., violinists and guitarists), woodwind players (e.g., flautists and clarinetists), and brass musicians (e.g., trombonists and trumpeters) (Gambichler et al. 2004). Skin conditions associated with musical instruments include a variety of allergic contact sensitizations (e.g., colophony (Murphy et al. 1999) and nickel (Jue et al. 2010)). In addition, the localization of dermatitis tends to be instrument-specific (e.g., "fiddler's neck" (Peachey and Matthews 1978; Jue et al. 2010; Caero and Cohen 2012), "cellist's chest" (Mandell 1962), "guitar nipple" (Curtis 1974), and "flautist's chin" (Dahl 1978)).

\section{Conclusions}

Despite the physical, mental, and emotional benefits of playing musical instruments, this activity is also associated with numerous health issues. While the majority of these issues are not serious, they can have fatal consequences in rare cases. These issues can be observed in both professional and amateur players, and all instrumentalists should be aware of the possible hazards and take the necessary precautions to reduce these risks. Physicians and surgeons, regardless of specialty, should also pay close attention to these potential health problems due to the wide range of presentations across multiple organ systems.

\section{Conflict of Interest}

The authors declare no conflict of interest.

\section{References}

Anaraki, S., Addiman, S., Nixon, G., Krahe, D., Ghosh, R., Brooks, T., Lloyd, G., Spencer, R., Walsh, A., McCloskey, B. \& Lightfoot, N. (2008) Investigations and control measures following a case of inhalation anthrax in East London in a drum maker and drummer. Euro Surveill., 13.

Basner, M., Babisch, W., Davis, A., Brink, M., Clark, C., Janssen, S. \& Stansfeld, S. (2014) Auditory and non-auditory effects of noise on health. Lancet, 383, 1325-1332.

Bouhuys, A. (1969) Physiology and Musical Instruments. Nature, 221, 1199-1204.

Bragge, P., Bialocerkowski, A. \& McMeeken, J. (2006) A systematic review of prevalence and risk factors associated with playing-related musculoskeletal disorders in pianists. Occup. Med. (Lond), 56, 28-38.

Caero, J.E. \& Cohen, P.R. (2012) Fiddler's neck: chin rest-associated irritant contact dermatitis and allergic contact dermatitis in a violin player. Dermatol. Online J., 18, 10.

Campbell, J.M. (1932) Acute symptoms following work with hay. $B M J, 2,1143-1144$.

Centers for Disease Control and Prevention (CDC) (2006) Inhalation anthrax associated with dried animal hides: Pennsylvania and New York City, 2006. JAMA, 295, 1991-1993.

Centers for Disease Control and Prevention (CDC) (2008) Cutaneous anthrax associated with drum making using goat hides from West Africa: Connecticut, 2007. MMWR Morb. Mortal. Wkly. Rep., 57, 628-631.

Centers for Disease Control and Prevention (CDC) (2010) Gastrointestinal anthrax after an animal-hide drumming event - New Hampshire and Massachusetts, 2009. MMWR Morb. Mortal. Wkly. Rep., 59, 872-877. 
Curtis, P. (1974) Letter: Guitar nipple. Br. Med. J., 2, 226.

Dahl, M.G. (1978) Flautist's chin: a companion to fiddler's neck. Br. Med. J., 2, 1023.

David, S., Salluzzo, R.F., Bartfield, J.M. \& Dickinson, E.T. (1997) Spontaneous cervicothoracic epidural hematoma following prolonged valsalva secondary to trumpet playing. Am. J. Emerg. Med., 15, 73-75.

Deniz, O., Savci, S., Tozkoparan, E., Ince, D.I., Ucar, M. \& Ciftci, F. (2006) Reduced pulmonary function in wind instrument players. Arch. Med. Res., 37, 506-510.

Dickson, S.D. \& Tankersley, M.S. (2015) Fatal hypersensitivity pneumonitis from exposure to fusarium vasinfectum in a home environment: a case report. Int. Arch. Allergy Immunol., 166, 150-153.

Dixon, T.C., Meselson, M., Guillemin, J. \& Hanna, P.C. (1999) Anthrax. N. Engl. J. Med., 341, 815-826.

Fasanella, A., Galante, D., Garofolo, G. \& Jones, M.H. (2010) Anthrax undervalued zoonosis. Vet. Microbiol., 140, 318-331.

Fiz, J.A., Aguilar, J., Carreras, A., Teixido, A., Haro, M., Rodenstein, D.O. \& Morera, J. (1993) Maximum respiratory pressures in trumpet players. Chest, 104, 1203-1204.

Flores-Franco, R.A. \& Limas-Frescas, N.E. (2010) The overused airway: lessons from a young trumpet player. Med. Probl. Perform. Art., 25, 35-38.

Fuhrmann, A., Wijsman, S., Weinstein, P., Poulsen, D. \& Franklin, P. (2009) Asthma among musicians in Australia: is there a difference between wind/brass and other players? Med. Probl. Perform. Art., 24, 170-174.

Fuhrmann, A.G., Franklin, P.J. \& Hall, G.L. (2011) Prolonged use of wind or brass instruments does not alter lung function in musicians. Respir. Med., 105, 761-767.

Gambichler, T., Boms, S. \& Freitag, M. (2004) Contact dermatitis and other skin conditions in instrumental musicians. $B M C$ Dermatol., 4, 3.

Garber, M.W. (1987) Pneumoparotitis: an unusual manifestation of hay fever. Am. J. Emerg. Med., 5, 40-41.

Gilbert, T.B. (1998) Breathing difficulties in wind instrument players. Md. Med. J., 47, 23-27.

Girard, M., Lacasse, Y. \& Cormier, Y. (2009) Hypersensitivity pneumonitis. Allergy, 64, 322-334.

Glowacka, A., Matthews-Kozanecka, M., Kawala, M. \& Kawala, B. (2014) The impact of the long-term playing of musical instruments on the stomatognathic system: review. Adv. Clin. Exp. Med., 23, 143-146.

Goel, A.K. (2015) Anthrax: a disease of biowarfare and public health importance. World J. Clin. Cases, 3, 20-33.

Goguen, L.A., April, M.M., Karmody, C.S. \& Carter, B.L. (1995) Self-induced pneumoparotitis. Arch. Otolaryngol. Head Neck Surg., 121, 1426-1429.

Gudlaugsson, O., Geirsson, A.J. \& Benediktsdottir, K. (1998) Pneumoparotitis: a new diagnostic technique and a case report. Ann. Otol. Rhinol. Laryngol., 107, 356-358.

Gunst, V., Huybrechts, B., De Almeida Neves, A., Bergmans, L., Van Meerbeek, B. \& Lambrechts, P. (2011) Playing wind instruments as a potential aetiologic cofactor in external cervical resorption: two case reports. Int. Endod. J., 44, 268-282.

Guzel, A., Simsek, O., Karasalihoglu, S., Kucukugurluoglu, Y., Acunas, B., Tosun, A. \& Cakir, B. (2007) Spontaneous spinal epidural hematoma after seizure: a case report. Clin. Pediatr., 46, 263-265.

Hagberg, M., Thiringer, G. \& Brandstrom, L. (2005) Incidence of tinnitus, impaired hearing and musculoskeletal disorders among students enrolled in academic music education: a retrospective cohort study. Int. Arch. Occup. Environ. Health, 78, 575-583.

Han, S. \& Isaacson, G. (2004) Recurrent pneumoparotid: cause and treatment. Otolaryngol. Head Neck Surg., 131, 758-761.

Hayashi, D., Kondou, Y., Nobuoka, D., Watanabe, T., Moriyama,
H., Nonaka, Y., Miyashima, T., Kurose, M. \& Tokuda, N. (2003) Review of cases of idiopathic mediastinal emphysema encounted at our hospital. M. J. Tsuyama C. H., 17, 3-7 (in Japanese).

Higuchi, S., Irie, E., Ishihara, S., Kobayashi, H., Arai, T. \& Dobashi, K. (2011) A case of hypersensitivity pneumonitis associated with home ultrasonic humidifier (humidifier lung). Occup. Environ. Allergy, 18, 57-63 (in Japanese).

Ito, S., Takada, Y., Tanaka, A., Ozeki, N. \& Yazaki, Y. (1989) A case of spontaneous peumomediastinum in a trombonist. Respiration \& Circulation, 37, 1359-1362 (in Japanese, abstract in English).

Jiang, W., Zhao, F., Guderley, N. \& Manchaiah, V. (2016) Daily music exposure dose and hearing problems using personal listening devices in adolescents and young adults: a systematic review. Int. J. Audiol., 55, 197-205.

Jue, M.S., Kim, Y.S. \& Ro, Y.S. (2010) Fiddler's neck accompanied by allergic contact dermatitis to nickel in a viola player. Ann. Dermatol., 22, 88-90.

Kimura, H., Watanabe, Y., Mizukoshi, K., Yamamoto, Y. \& Araki, S. (1993) Six cases of anesthesia mumps. Nippon Jibiinkoka Gakkai Kaiho, 96, 1915-1921 (in Japanese).

King, J., Richardson, M., Quinn, A.M., Holme, J. \& Chaudhuri, N. (2017) Bagpipe lung; a new type of interstitial lung disease? Thorax, 72, 380-382.

Klempner, M.S., Talbot, E.A., Lee, S.I., Zaki, S. \& Ferraro, M.J. (2010) Case records of the Massachusetts General Hospital. Case 25-2010: a 24-year-old woman with abdominal pain and shock. N. Engl. J. Med., 363, 766-777.

Kovero, O., Könönen, M. \& Pirinen, S. (1997) The effect of violin playing on the bony facial structures in adolescents. Eur. $J$. Orthod., 19, 369-375.

Kyung, S.K., Heurtebise, F., Godon, A., Riviere, M.F. \& Coatrieux, A. (2010) Head-neck and mediastinal emphysema caused by playing a wind instrument. Eur. Ann. Otorhinolaryngol. Head Neck Dis., 127, 221-223.

le Clercq, C.M.P., van Ingen, G., Ruytjens, L. \& van der Schroeff, M.P. (2016) Music-induced hearing loss in children, adolescents, and young adults: a systematic review and meta-analysis. Otol. Neurotol., 37, 1208-1216.

Lederman, R.J. (2003) Neuromuscular and musculoskeletal problems in instrumental musicians. Muscle Nerve, 27, 549-561.

Lindhorst, E. \& Paolucci, V. (2000) Saxophone spermatic cord hematoma. Am. J. Emerg. Med., 18, 504-505.

Lodha, S., Maria, S. \& Sharma, O.P. (1988) Hypersensitivity pneumonitis in a saxophone player. Chest, $\mathbf{9 3}, 1322$.

Lonsdale, K., Laakso, E.L. \& Tomlinson, V. (2014) Contributing factors, prevention, and management of playing-related musculoskeletal disorders among flute players internationally. Med. Probl. Perform. Art, 29, 155-162.

Luaces, R., Ferreras, J., Patino, B., Garcia-Rozado, A., Vazquez, I. \& Lopez-Cedrun, J.L. (2008) Pneumoparotid: a case report and review of the literature. J. Oral Maxillofac. Surg., 66, $362-365$.

Macia, I., Moya, J., Ramos, R., Morera, R., Escobar, I., Saumench, J., Perna, V. \& Rivas, F. (2007) Spontaneous pneumomediastinum: 41 cases. Eur. J. Cardiothorac. Surg., 31, 1110-1114.

Mandell, H.N. (1962) Cellist's chest. N. Engl. J. Med., 266, 348.

Marshall, B. \& Levy, S. (2011) Microbial contamination of musical wind instruments. Int. J. Environ. Health Res., 21, 275-285.

McGreevy, A.E., O'Kane, A.M., McCaul, D. \& Basha, S.I. (2013) Pneumoparotitis: a case report. Head Neck, 35, E55-E59.

Mete, A., Kimyon, S., Saygili, O., Evisen, A., Pamukcu, C., Ceri, S. \& Gungor, K. (2016) Dynamic changes in optic disc morphology, choroidal thickness, anterior chamber parameters, and intraocular pressure during Valsalva maneuver. Arq. Bras. Oftalmlol., 79, 209-213.

Metersky, M.L., Bean, S.B., Meyer, J.D., Mutambudzi, M., Brown- 
Elliott, B.A., Wechsler, M.E. \& Wallace, R.J. Jr. (2010) Trombone player's lung: a probable new cause of hypersensitivity pneumonitis. Chest, 138, 754-756.

Metzger, F., Haccuria, A., Reboux, G., Nolard, N., Dalphin, J.C. \& De Vuyst, P. (2010) Hypersensitivity pneumonitis due to molds in a saxophone player. Chest, 138, 724-726.

Moraes, G.F. \& Antunes, A.P. (2012) Musculoskeletal disorders in professional violinists and violists. Systematic review. Acta Ortop. Bras., 20, 43-47.

Mori, T. (2000) Recent trends in tuberculosis, Japan. Emerg. Infect. Dis., 6, 566-568.

Murphy, J., Clark, C., Kenicer, K. \& Green, C. (1999) Allergic contact dermatitis from colophony and Compositae in a violinist. Contact Dermatitis, 40, 334.

Nakagawa, A., Yamaguchi, T. \& Amano, H. (1995) A case of hypersensitivity pneumonitis probably caused by a humidifier in winter. Jpn. J. Thorac. Dis., 33, 202-208 (in Japanese, abstract in English).

Nohga, S., Yoshida, K., Iwasa, K., Sakurai, T., Akabane, R., Date, K., Koike, T., Korai, Y., Maeda, A. \& Miyaji, H. (1989) Tuberculosis transmission among university students (3). The Report of the 26th Annual Meeting of Japan University Health Association, 26, 62-63.

Nyman, T., Wiktorin, C., Mulder, M. \& Johansson, Y.L. (2007) Work postures and neck-shoulder pain among orchestra musicians. Am. J. Ind. Med., 50, 370-376.

Pouryaghoub, G., Mehrdad, R. \& Pourhosein, S. (2017) NoiseInduced hearing loss among professional musicians. J. Осcup. Health, 59, 33-37.

Owen, J.L., Yang, T. \& Mohamadzadeh, M. (2015) New insights into gastrointestinal anthrax infection. Trends Mol. Med., 21, 154-163.

Peachey, R.D. \& Matthews, C.N. (1978) 'Fiddler's neck'. Br. J. Dermatol., 98, 669-674.

Piette, E. \&Walker, R.T. (1991) Pneumoparotid during dental treatment. Oral Surg. Oral Med. Oral Pathol., 72, 415-417.

Prasad, K.C., Vijayalakshmi, S. \& Prasad, S.C. (2008) Laryngoceles: presentations and management. Indian J. Otolaryngol. Head Neck Surg., 60, 303-308.

Rackley, C.R. \& Meltzer, E.B. (2011) Throw caution to the wind instruments. Chest, 139, 729; author reply 729-730.

Reilly, D.J. (1970) Benign transient swelling of the parotid glands following general anesthesia: "anesthesia mumps". Anesth. Analg., 49, 560-563.

Riaz, S., Jiang, H., Fox, R., Lavoie, M. \& Mahood, J.K. (2007) Spontaneous spinal epidural hematoma causing brownsequard syndrome: case report and review of the literature. $J$. Emerg. Med., 33, 241-244.

Rietveld, A.B.M. (2007) Performing Arts Medicine Abroad.
Genees \& Kunst 3: third biannual symposium on medical problems of dancers and musicians. Med. Probl. Perform. Art., 22, 30-35.

Ruano-Ravina, A., Figueiras, A. \& Barros-Dios, J.M. (2003) Musicians playing wind instruments and risk of lung cancer: is there an association? Occup. Environ. Med., 60, 143.

Santucci, M. (2009) Protecting musicians from hearing damage: a review of evidence-based research. Med. Probl. Perform. Art., 24, 103-107.

Saunders, H.F. (1973) Wind parotitis. N. Engl. J. Med., 289, 698.

Schink, T., Kreutz, G., Busch, V., Pigeot, I. \& Ahrens, W. (2014) Incidence and relative risk of hearing disorders in professional musicians. Occup. Environ. Med., 71, 472-476.

Schmidtmann, G., Jahnke, S., Seidel, E.J., Sickenberger, W. \& Grein, H.J. (2011) Intraocular pressure fluctuations in professional brass and woodwind musicians during common playing conditions. Graefes Arch. Clin. Exp. Ophthalmol., 249, 895-901.

Schuman, J.S., Massicotte, E.C., Connolly, S., Hertzmark, E., Mukherji, B. \& Kunen, M.Z. (2000) Increased intraocular pressure and visual field defects in high resistance wind instrument players. Ophthalmology, 107, 127-133.

Sihota, R., Dada, T., Aggarwal, A., Srinivasan, G., Gupta, V. \& Chabra, V.K. (2008) Does an iridotomy provide protection against narrowing of the anterior chamber angle during Valsalva maneuvre in eyes with primary angle closure. Eye (Lond), 22, 389-393.

Stell, P.M. \& Maran, A.G. (1975) Laryngocoele. J. Laryngol. Otol., 89, 915-924.

Stormer, C.C., Laukli, E., Hoydal, E.H. \& Stenklev, N.C. (2015) Hearing loss and tinnitus in rock musicians: a Norwegian survey. Noise Health, 17, 411-421.

Sweeney, D.A., Hicks, C.W., Cui, X., Li, Y. \& Eichacker, P.Q. (2011) Anthrax infection. Am. J. Respir. Crit. Care Med., 184, 1333-1341.

Takagi, T., Kobayashi, T., Fujiwara, K., Onishi, M., Naito, M., Kobayashi, H., Gabazza, E.C. \& Taguchi, O. (2012) A case of hypersensitivity pneumonitis with recurrent exacerbation in winter. Occup. Environ. Allergy, 19, 41-48 (in Japanese).

Vosk, A. (2009) Bagpiper's hernia. Med. Probl. Perform. Art., 24, 97-98.

Walter, W.G. \& Chaffey, D. (1959) Bacteriological and cleaning studies on the mouthpieces of musical instruments. Appl. Microbiol. (Los Angel), 7, 126-130.

Watt, J. (1977) Benign parotid swellings: a review. Proc. R. Soc. Med.,70, 483-486.

Zelenik, K., Stanikova, L., Smatanova, K., Cerny, M. \& Kominek, P. (2014) Treatment of Laryngoceles: what is the progress over the last two decades? Biomed Res. Int., 2014, 819453. 